\title{
Patella Bipartita
}

Ömer Özkan ${ }^{1}$, Gürhan Dönmez ${ }^{1}$, Melda Pelin Yargıç ${ }^{1}$, Mahmut Nedim Doral ${ }^{2}$

Öz

\author{
${ }^{1}$ Hacettepe Üniversitesi, Spor Hekimliği Ad, Ankara, Turkey \\ ${ }^{2}$ Hacettepe Üniversitesi, Ortopedi Ve Travmatoloji Ad, Ankara, Turkey
}

Bipartite patella - patella bipartita olarak da bilinen, genellikle patellanın insidental ve asemptomatik saptanan bir bulgusudur. Buna rağmen, genellikle adolesan hastalarda olmak üzere tekrarlayan spor aktivitelerini takiben ya da akut travma sonrası ön diz ağrısı ortaya çıkabilir. Semptomatik hastalarda tedavinin en önemli basamağı ağrı yaratan aktivitelerden kaçınmaktır. Çoğu hastada konservatif yaklaşımla sonuç alınır. Cerrahi tedavi yalnızca konservatif yaklaşımdan sonuç alınamazsa düşünülmelidir. Aksesuar fragmanın eksizyonu en çok tercih edilen cerrahi yöntem olup oldukça iyi sonuçlar bildirilmiştir. Diğer cerrahi seçenekler; lateral retinakuler gevşetme, vastus lateralis kası gevşetmesi ve ayrılmış fragmanın internal fiksasyonudur. Ağrılı bipartite patellada farklı tedavi yaklaşımlarının olası sonuçlarını anlamak için; patellofemoral eklem fonksiyonunu ve kuadriceps kas gücünü korumak gereklidir.

Anahtar sözcükler: Patella, aksesuar kemik, varyasyon

\section{Patella Bipartita}

\begin{abstract}
Bipartite patella also known as patella bipartite, is a condition that is usually an asymptomatic and incidental finding of patella. Nevertheless, it can be a cause of anterior knee pain following acut trauma or a result of overuse or strenuous sports activity seen generally in adolesant patients. The usual treatment for symptomatic bipartite patella is to avoid painful activities. Most patients recover with nonsurgical treatment. Surgery should be considered when only nonsurgical treatment fails. Excision of the fragment is the most preferred surgical option which has good outcomes. Other surgical options are; lateral retinacular release, detachment of the vastus lateralis muscle and internal fixation of the separated fragment. Understanding the possible consequences of different treatment approaches to painful bipartite patella is necessary to preserve quadriceps muscle strength and patellofemoral joint function.
\end{abstract}

Key words: Patellae, accessory ossicle, variation 


\section{GíRis}

Patella ekstansör mekanizmada yer alan, kabaca üçgen şeklinde sesamoid bir kemiktir ve diz ekleminin ön bölümünde yerleşmiştir. Yerleşimi nedeni ile diz eklemini doğrudan darbelere karşı korur ve femurun patellofemoral eklem yüzü kıkırdağının beslenmesine yardımcı olur. Patella tabanı (basis patellae) üstte, tavanı ise (apex patellae) altta, taban köșeleri yuvarlaklașmıș, dik açılı bir ikizkenar üçgene benzer. Kuadriseps tendonu içinde gelişmiş ve vücudun en büyük sesamoid kemiği olan patella ortalama $5 \times 6 \times 3 \quad \mathrm{~cm}$ boyutlarındadır (1). Patella embriyolojik olarak 8. haftada diz boșluğu ve kas taslağından önce, kuadriseps taslağının altında oluşur. Araștırmalara göre patella genelde (\%75) tek bir ossifikasyon merkezinden gelişmektedir $(2,3)$. Primer ossifikasyon merkezi kızlarda 21-54. aylar arasında erkelerde ise 36-72. aylar arasinda ortaya çlkmaktadır (2). Ancak bazı olgularda kemik oluşumunda ikinci hatta üçüncü bir ossifikasyon merkezi söz konusudur. Eğer bu iki kemikleşme merkezi er geç birleşemezse, ana kemik dışında patellaya fibrokartilaj doku ile bağlanan bir aksesuar kemik daha meydana gelir. Sıklıkla patella üst dış bölümünde oluşan patella bipartita ilerideki yaşamda patella kırıklarıyla karıştırılabilir (4) (Resim 1).
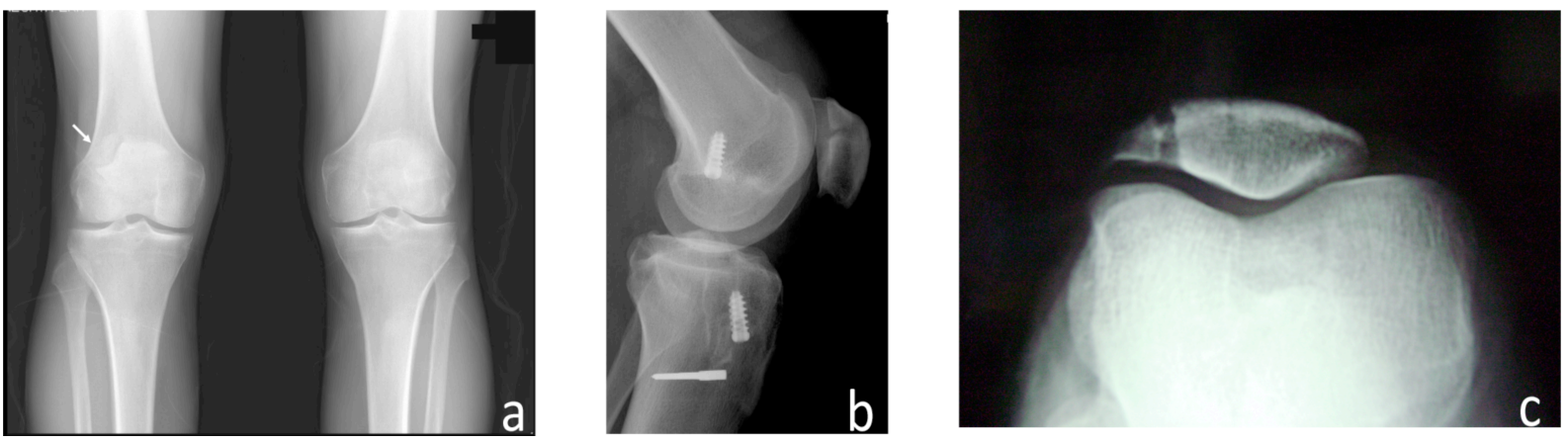

Resim 1: a. 54 yaşında diz ağrısı olan bir hastada insidental saptanan sağ dizde bipartite patella ön-arka direkt grafisi. b. Ön çapraz bağ rekonstrüksiyonu öyküsü olan 28 yaşında profesyonel bir basketbolcuda lateral direkt grafide bipartite patella görüntüsü. c. Tanjansiyel grafide bipartite patella görüntüsü

Patella bipartita; ilk kez 1883 yılında Gruber tarafından 21 yaşında bir çiftçide patellanın büyük alt-iç ve küçük üst-dış olarak iki fragmandan oluştuğunu tespit etmesiyle vaka olarak rapor edilmiştir (5). Daha sonra 1943 yilında Saupe tarafından patelladan ayrık görülen fragmanın yerleşimine göre; patella alt kutbunda tip 1 (\%5), patella lateral kenarında tip $2(\% 20)$ ve patella superolateralinde tip 3 (\%75) olarak sinıflandırılmıștır (6). Saupe'nin sinıflaması sadece aksesuar fragmanın lokalizasyonu temelli olduğu için eleștirilmektedir. Etiyoloji bu siniflamada yer tutmamakta olup tripartit patella ve daha az görülen medial bipartite patellayı kapsamamaktadır (7) (Resim 2). Patella bipartitanın karakteristik aksesuar ossifikasyon merkezi superolateral kadranda bulunur. Bipartite patella konjenitaldir ve gelişimsel bir varyasyon olduğu düşünülmektedir. Ancak etiyolojisi tam olarak aydınlatılamamıştır ve kalıtımsal 
(herediter) olmadığı düşünülmektedir (8). Eski minor travma, osteokondritis oluşumu ve konjenital büyüme defektleri olası diğer etiyolojik faktörler olabilir (9). Toplumdaki sıklığının \%1-2 civarında olduğu tahmin edilmektedir. Bunların \%50'si bilateraldir ve erkeklerde daha sık görülür (10).

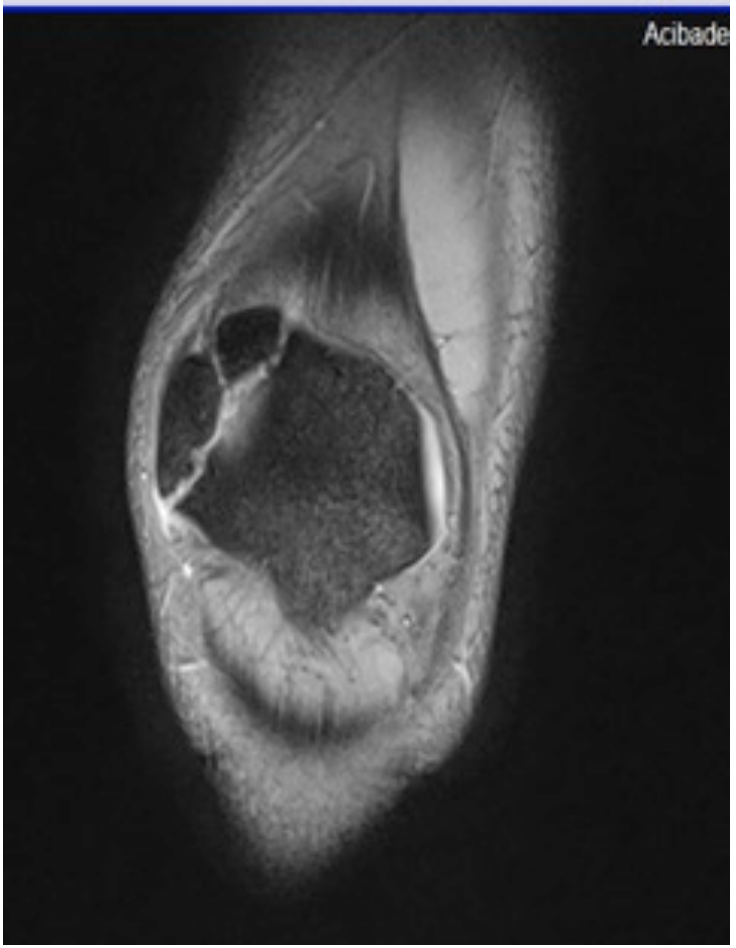

Resim 2: 21 yaşında profesyonel futbolcuda tripartit patella koronal MR görüntüsü

\section{KLINIIK}

Bipartite patellanın genellikle klinik öneme sahip olmadığı düşünülmüştür. $\mathrm{Bu}$ kemikçik çoğunlukla anatomik ve radyolojik araștırmalarda rastlantısal olarak karșılașılan asemptomatik bir varyasyondur. Fakat son zamanlarda, bu kemikçiğin diz önü ağrısına sebep olabileceğine dair görüşler öne çıkmaktadır. Semptomatik bipartite patella olguları $\% 2$ civarında bildirilmiş olup bir veya daha çok sayıda (multipartit) sekonder ossifikasyon merkezi künt travma veya yineleyen travmalarla semptomatik hale gelebilir (3). Kimi zaman patelladaki kemik parçalarını bağlayan zayıf fibröz dokunun zorlanması ya da ayrilması, özellikle sıçrama sporlarında, merdiven çıkma esnasında ya da dizin fleksiyonunu gerektiren hareketler de tekrarlayan ağrıya yol açabilir. Aksesuar patella ile patella arasındaki kıkırdak dokuda meydana gelen bir kırık ve kıkırdak dokunun yeterli iyileşme göstermemesi, semptomların ortaya çıkmasına neden olmaktadır (11).

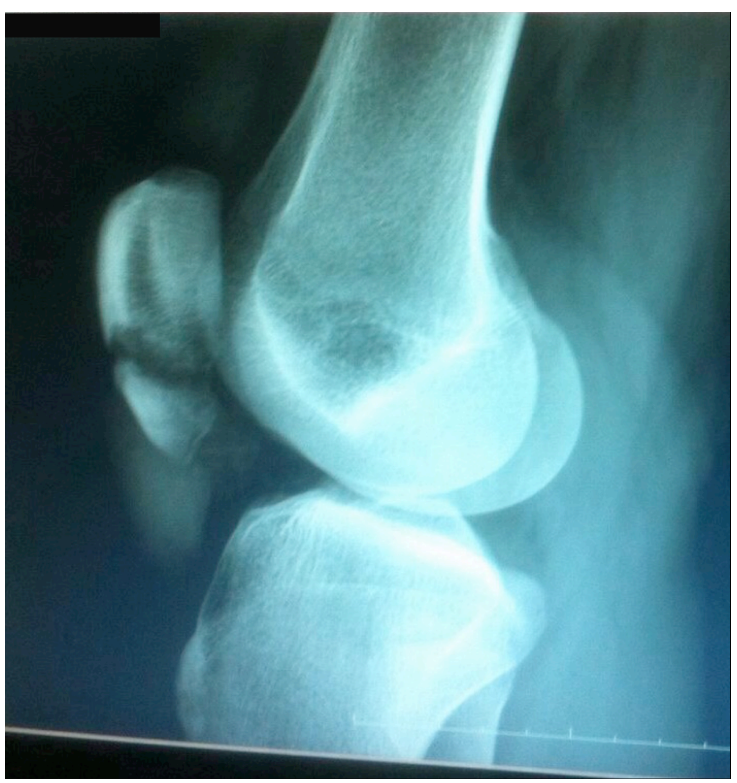

Resim 3: 17 yașında bir hastada travmatik patella kırığı lateral grafisi

\section{TANI}

Fizik muayenede patella büyük gibidir ve fragmanın patellaya bağlantı yeri hassas olabilir. Dirence karşı ekstansiyon ve yere çömelme ile aynı yerde ağrı görülebilir. Daha nadiren superolateral bölgede duyarlılık, efüzyon, hematom gibi bulgular da eşlik edebilir. Özellikle ön-arka ve tanjansiyel grafilerde fragman kolaylıkla görülebilir (Resim 1); yanlışlıkla patellanın avülziyon kırığı olarak değerlendirilebilir. Bipartite patellada düzensiz bir hatla ayrılmış iki parça, kırık patellada ise kenarları keskin düz bir hat izlenir (Resim 3). Bipartite 
patellanın travmatik olarak ayrılmasının, ossifikasyon merkezleri arasındaki kartilaj bağlantının tekrarlayan mikrotravmalarla, inflamasyon ve kronik stresler nedeniyle zayıflaması sonucunda meydana geldiğine inanılmaktadır. Ayrıca, düşük şiddetteki travmalar bile travmatik ayrılma için yeterli olabilmektedir (4). Bipartite patellanın kırı $\breve{g}$ ise literatürde oldukça nadir tanımlanmış ve özellikle sporcunun performansının düşmesinde gözden kaçabilecek nedenlerden biri olarak öne sürülmüștür (12). 40 yaş üzerinde kuadrisepse ekzentrik yüklenmeler sonucunda gelişen kuadriseps rüptürleri bildirilmiştir (3).

Daha önce belirtildiği gibi bipartite patellanın tanısı genelde radyolojik olarak raslantısal konulmaktadır. Semptomatik ve asemptomatik olguların radyolojik olarak ayırt edilebilmesine dair yapılan bipartite patellalı 37 olguluk bir çalışmada kemik sintigrafisi semptomatik ve asemptomatik bipartite patellaların ayrımında yetersiz bulunmuştur (13). Her iki grupta da anormal yüksek sintigrafik tutulum saptanmış ve arada anlamlı bir fark bulunamamıștır. Sintigrafik bulgulara göre cerrahi kararının verilmesi önerilmemektedir.

Manyetik rezonans görüntülemede (MRG), asemptomatik bipartite patella, patella ile fragmanı arasındaki intakt ancak incelmiș artiküler kartilaj sınırları ve patella ile fragmanı arasındaki sinyal intensitesi artışı ve kemik iliği ödemi yokluğu ile ayrılır (14). Kavanagh ve arkadaşlarının MRG çalışmasında aksesuar fragmandaki kemik iliği varlığ bipartite patellalı ve ön diz ağrısı mevcut hastaların \%49'undaki tek bulgu olarak raporlanmıștır (15). Bipartite patellada ultrasonografik görüntüleme kemik kontürlerinde düzensizlik, aksesuar fragman ile ana kemik yapı arasındaki boşluğu görüntülemede kullanılabilir.
Kemikler arasındaki daha az ekojenik bölge; fibrokartilaj yapıya karşılık gelir (16).

\section{TEDAVİ}

\section{Konservatif Tedavi}

Semptomatik bipartite patellalı vakaların çoğu konservatif olarak tedavi edilmektedir. Akut olgularda fragman ile patella arasındaki ayrılmaya bağlı ağrı oluşur. Ağrılı durumlarda dizin istirahati, siçrama hareketlerinin sınırlandırılması gibi yöntemler ve 3 haftalı immobilizasyon önerilir. Kuadriseps ve hamstring kaslarının germe ve kuvvetlendirme egzersizleri de faydalı olabilir. Kronik olgularda ise 3-4 haftalık aktivite kısıtlaması ile iyileşme elde edilebilir (12). Patellaya bağlanan fibröz dokuda ayrılma olduysa hastalara 4-6 hafta süreyle alçı ya da diz immobilizatörü önerilebilir.

Semptomatik bipartite patellalı hastalarda, 6 haftalık ağrılı aktivitelerden kaçınma ve kuadriseps kas güçlendirme egzersizleri ile ağrıların kaybolduğu bildirilmiștir (17). Okuno ve arkadaşları immobilizasyonun etkisini değerlendirdikleri çalışmalarında; genç yaşta indirekt patella travmasına maruz kalmış, sinkondroz boyunca uzanan kırığı olan hastaların 3 ay boyunca immobilize edildikten sonra 3 . ayda spora tam dönüşlerininin sağlandığı ve 4. ayda kırık hattı kaynamasının gerçekleștiğini bildirmişlerdir (18). İstirahat ve antiinflamatuar tedaviye yanıt vermeyen ağrılı hastalarda lokal bupivakain ve metilprednizolon tedavisi ile semptomatik rahatlama bildirilmiștir (19). Fizik tedavi modalitelerinde düşük intensiteli 20 dakikalık ultrason terapisi ile semptomlarda rahatlama gözlenmiştir (20). Ağrı inatçı ve sürekli hale geldiyse ve konservatif tedavi ile yakınmalar geçmezse bipartite patellanın cerrahi olarak eksizyonuna 
ihtiyaç duyulabilir ve bu işlemle iyi sonuçlar alınabilir.

\section{Cerrahi Tedavi}

Semptomatik bipartite patellası olan hastaların tedavisi için çok çeşitli cerrahi yöntemler bildirilmiștir. Bunlardan sıklıkla uygulananları; artroskopik eksizyon, açık cerrahi eksizyon, Gergi bandı ile telleme, açık redüksiyoninternal fiksasyon ve yumuşak doku gevşetmeleridir. (21). Bunların dışında açık parsiyel patellektomi invazif ve post-op uzun süre rehabilitasyon gerektiren bir yöntem olarak değerlendirilmektedir.

Bugüne dek yayımlanan çok sayıda çalışmada ve olgu sunumlarında artroskopik eksizyon ile bipartite patellası olan hastaların uzun dönem takiplerinde semptomatik rahatlama gözlendiği ve fonksiyonel kayıp olmadı̆̆ı bildirilmiştir (22-25) (Resim 4). Açık cerrahi eksizyon ise dirençli semptomatik bipartite patellalı hastalarda en sik rapor edilen yöntemdir. Ireland ve ark.larının bir çalışmasında ise 47 yaşında erkek hastada tip 3 fragman eksizyonunu takiben 4 ayda spora tam dönüş ve takip eden dönemde ağrıların geçtiği bildirilmiştir (26). Benzer şekilde açık cerrahi eksizyon ile uzun dönem takipte başarılı sonuçlar bildiren daha geniş hasta serileri de mevcuttur $(27,28)$. Weckstrom ve ark.larının 25 erkek hastada yaptığı retrospektif çalışmada en az 10 yıl süreyle takip edilen hastaların klinik skorlarında belirgin iyileşme gözlenmiş ve Kujala skoru ortalaması 95, VAS (visual analog scale) ise 1.0 olarak bildirilmiștir (29).
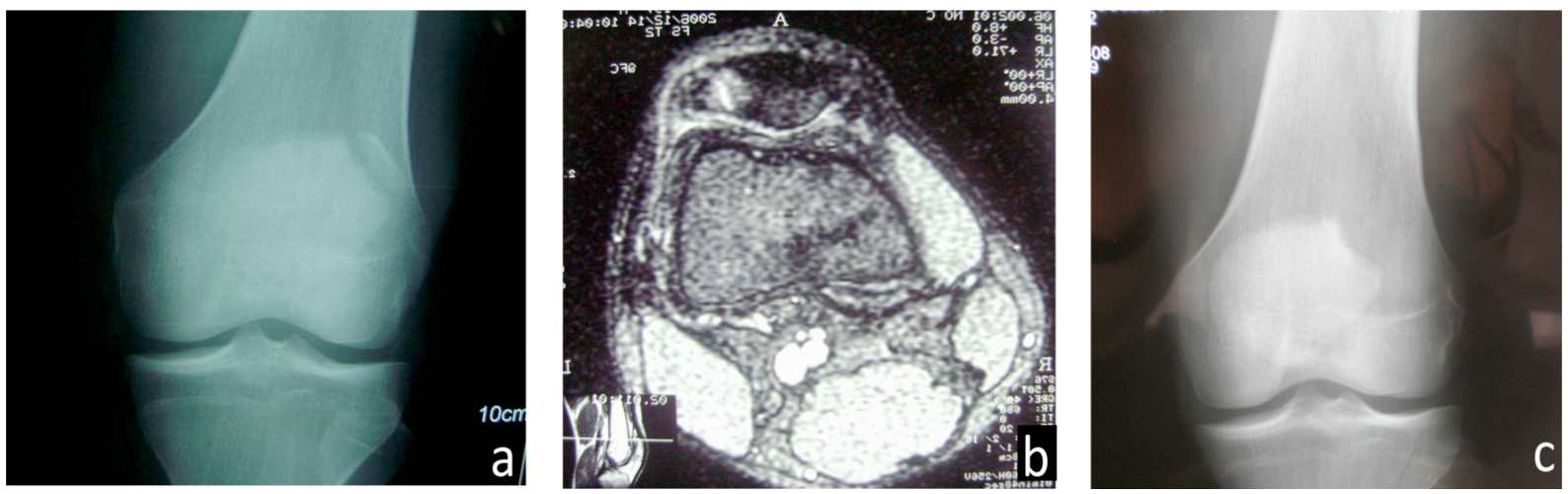

Resim 4: Artroskopik patella lateral üst pol eksizyonu yapılan 21 yaşında semptomatik bipartite patella olgusunun a. Preop ön-arka grafisi b. Aksiyel MR görüntüsü c. Postop ön-arka grafisi

Öte yandan 3 farklı bipartite patella vaka raporunda gergi bandı ile telleme işlemi uygulanmiştır $(4,18,30)$. Her üç olgu da patellaya direkt bir travma öyküsü mevcut olmayan spor yapan genç hastalar iken iki vakada 3. ve 4. aylarda kaynama sağlanmış $(18,30)$ ancak diğer olguda 29. ayda uzun surely egzersizden sonra ağrıların devam ettiği bildirilmiştir (4).
Adachi ve ark.ları ağrılı 15 bipartite patella olgusunda vastus lateralis gevşetme tekniğinin etkinliğini değerlendirmiş, açık metod ile holmium YAG lazer sistemi (OmniPulse Holmium Laser System; Trimedyne Inc, Irvine, CA) kullanilan artroskopik metodu karşılaştırmışlardır (31). Operasyondan 4 hafta sonra tüm hastalarda fragman üzerindeki ağrı kaybolurken, hastaların hepsinin eski sportif aktivitelerine 3 ay 
içinde döndüğü bildirilmiştir (31). Kemik birleșimi (bone union) 6 ay sonra \%64.7 hastada tamamlanmıș, \%35.3 hastada ise tamamlanmamıș olduğu görülmüștür. Kemik birleşimi 15 yaş altı hastalarda belirgin olarak daha iyidir. Artroskopik olarak uygulanan gevşetme tekniğinde dizdeki efüzyonun kaybolması ve kas kuvvetinin geri dönüșü istatistiksel olarak daha iyi olarak saptanmıştır. Sonuçta Adachi ve ark.ları vastus lateralis gevşetme tekniğini daha az invazif olduğu ve daha iyi sonuçlar verdiği gerekçesiyle ağrılı bipartite patella tedavisinde ilk tercih olarak değerlendirmiştir (31). Bir başka çalışmada ise 15 hastada modifiye lateral retinakuler gevşetme tekniği kullanılmış ve bu teknikle patellanın sürekli lateral ve proksimale çekilmesi sonucu ağrı yaratan bipartite patella vakalarında çekme kuvveti azaltılarak ağrının rahatlatılması ve kemik birleşiminin gelişimi sağlanmıștır (32). Ağrılı bipartite patellanın aşırı lateral bası sendromuna ya da patellar kompresyon sendromuna yol açabileceği ve bu komplikasyonların bu cerrahi teknikle etkili olarak tedavi edilebileceği bildirilmiştir. Açlk redüksiyon internal fiksasyon (ARİF) tekniği ile ilgili çelişkili sonuçlar bulunmakta olup ARIF'in çok büyük aksesuar fragman mevcudiyetinde kullanımı daha uygun olarak bildirilmiştir (32).

\section{SONUC}

Bipartite patella, özellikle adolesan hastalarda ön diz ağrısının muhtemel nedenlerinden biri olarak değerlendirilmelidir. Hastaların değerlendirilmesinde anamnez ve fizik muayenenin yanısıra bilateral iki yönlü diz grafilerine mutlaka bakılmalıdır. Ayırıcı tanıda bilgisayarlı tomografi ve MRG seçenekler arasındadır. Cerrahi yalnızca, konservatif yaklașımların başarısız olduğu durumlarda endikedir. Vastus lateralis kasının patofizyolojik rolünün önemini kavramak, bipartite patellalı hastada cerrahi kararını vermede hayati önem içermektedir.

\section{KAYNAKLAR}

1. Smith JG: Biomechanical analysis of knee flexion Sebik A. Patellofemoral eklemin anatomisi ve biyomekanik özellikleri. Acta Orthop Traumatol Turc 1995; 29: 351-356

2. Canizares GH, Selesnick FH. Bipartite patella fracture. Arthroscopy 2003;19(2):215-217

3. Gorva AD, Siddique I, Mohan R. An Unusual Case of Bipartite Patella Fracture with Quadriceps Rupture Eur J Trauma 2006;32:411-413

4. Tauber M, Matis $N$, Resch H. Traumatic separation of an uncommon bipartite patella type : a case report. Knee Surg Sports Traumatol Arthrosc 2007:15:83-87

5. Gruber W. In bildungsanomalie mit bildungshemmung begründete bipartition beider patellae eines jungen subjectes. Archiv für Pathologische Anatomie und Physiologie und für Klinische Medicin. 1883;94(2):358-361

6. Saupe E. Beitrag zur patella bipartita. Fortschr Rontgenstr 1921;28:37-41

7. Oohashi Y, Koshino T, Oohashi Y. Clinical features and classification of bipartite or tripartite patella. Knee Surg Sports Traumatol Arthrosc 2010;18:1465-1469

8. Ogden JA, McCarthy SM, Jokl P. The painful bipartite patella. J Pediatr Orthop 1982;2(3):263269

9. Saupe H. Primare Knochenmark seilerung der Kniescheibe. Dtsche Z Chir 1943;258:386

10. Pınar H. İnstabilite dışı nedene bağlı diz önü ağrısı. Acta Orthop Traumatol Turc 2004;38 Suppl 1:108118

11. Aydınlıoğlu A, Tosun N, Arslan H, Akpınar F, Doğan A, Alıș T. The Accessory Patella. Ulus Travma Acil Cerrahi Derg. 1997;3(3):200-206

12. Weaver JK. Bipartite patellae as a cause of disability in the athlete. Am J Sports Med 1977;5(4):137-143

13. Oohashi $Y$, Koshino T Bone scintigraphy in patients with bipartite patella. Knee Surg Sports Traumatol Arthrosc. 2007;15(11):1395-1399

14. O'Brien J, Murphy C, Halpenny D, McNeill G, Torreggiani WC. Magnetic resonance imaging features of asymptomatic bipartite patella. Eur I Radiol. 2011;78:425-429.

15. Kavanagh EC, Zoga A, Omar I, Ford S, Schweitzer $M$, Eustace $S$. MRI findings in bipartite patella. Skeletal Radiol. 2007;36:209-214.

16. Blankstein A, Cohen I, Salai M, Diamant L, Chechick A, Ganel A. Ultrasonography: an imaging modality enabling the diagnosis of bipartite patella. Knee Surg Sports Traumatol Arthrosc 2001;9(4): 221224

17. Wong CK. Bipartite patella in a young athlete. J Orthop Sports Phys Ther 2009;39(7):560 
18. Okuno H, Sugita $T$, Kawamata $T$, Ohnuma $M$, Yamada N, Yoshizumi Y. Traumatic separation of a type I bipartite patella. Clin Orthop 2004;420:257260

19. Marya KM, Yadav V, Devagan A, Kundu ZS. Painful bilateral bipartite patellae - case report Indian J Med Sci 2003;57:66-67

20. Kumahashi N, Uchio Y, Iwasa J, Kawasaki K, Adachi $N$, Ochi M. Bone union of painful bipartite patella after treatment with low-intensity pulsed ultrasound: report of two cases. Knee 2007;15:5053

21. Atesok K, Doral MN, Lowe J, Finsterbush A. Symptomatic bipartite patella: treatment alternatives. J Am Acad Orthop Surg. 2008;16(8):455-461

22. Azarbod P, Agar G, Patel V. Arthroscopic excision of a painful bipartite patella fragment. Arthroscopy 2005;21(8):1006

23. Carney J, Thompson D, O'Daniel J, Cassidy J. Arthroscopic excision of a painful bipartite patella fragment. Am J Orthop 2010;39(1):40-43

24. Felli $L$, Fiore M, Biglieni L. Arthroscopic treatment of symptomatic bipartite patella. Knee Surg Sports Traumatol Arthrosc 2011;19(3):398-399

25. Yoo JH, Kim EH, Ryu HW. Arthroscopic removal of separated bipartite patella causing snapping knee syndrome. Orthopaedics 2008;31(7):717
26. Ireland $M L$, Chang JL. Acute fracture bipartite patella: case report and literature review. Med Sci Sports Exerc 1995;27(3):299-302

27. Bourne MH, Bianco AJ Jr. Bipartite patella in the adolescent: results of surgical excision. J Pediatr Orthop 1990;10: 69-73

28. Ishikawa H, Sakurai A, Hirata S, Ohno O, Kita K, Sato T, Kashiwagi D. Painful bipartite patella in young athletes. The diagnostic value of skyline views in squatting position and surgical excision. Clin Orthop Relat Res 1994;305:223-228

29. Weckström M, Parviainen M, Pihlajamäki HK. Excision of painful bipartite patella: good longterm outcome in young adults. Clin Orthop Relat Res 2008;466(11):2848-2855

30. Peek AC, Barry M. Patella fracture in a boy with bilateral inferior pole bipartite patellae. Knee 2012;19(5):716-718

31. Adachi N, Ochi M, Yamaguchi H, Uchio Y, Kuriwaka M. Vastus lateralis release for painful bipartite patella. Arthroscopy 2002;18(4):404-411

32. Mori Y, Okumo H, Iketani H, Kuroki Y. Efficacy of lateral retinacular release for painful bipartite patella. Am J Sports Med 1995;23(1):13-18 